\title{
ENSINO DE PORTUGUÊS COMO LÍNGUA DE ACOLHIMENTO: EXPERIÊNCIA EM UM CURSO DE PORTUGUÊS PARA IMIGRANTES E REFUGIADOS(AS) NO BRASIL
}

\author{
Mirelle Amaral de São Bernardo* \\ Lúcia Maria Assunção Barbosa
}

RESUMO: O Brasil tem recebido um número considerável de imigrantes de diferentes nacionalidades vindos da América do Sul, da África e de países como Bangladesh e Paquistão, mas principalmente haitianos, sírios. No entanto, o Brasil não conta, ainda, com políticas públicas explícitas para o ensino de português para essas pessoas. A sociedade civil e algumas universidades têm realizado essa tarefa com o objetivo de tentar minimizar obstáculos para integração das/os imigrantes relacionadas à dificuldade de comunicação. Ainda assim, existe a necessidade da ampliação e discussão do conceito de língua de acolhimento e de pesquisas que promovam ações efetivas de integração social, por meio do ensino da língua em contexto de acolhimento. Abordaremos neste artigo a (des)(re)construção do conceito de língua de acolhimento e apresentaremos a experiência do curso de português como língua de acolhimento, como parte do Projeto de Pesquisa: PROACOLHER: Português como Língua de Acolhimento, oferecido no NEPPE (Núcleo de Ensino e Pesquisa em Português como Língua Estrangeira) da Universidade de Brasília. A pesquisa-ação nos trouxe dados que consideramos relevantes para afirmar que o ensino de português em contexto de acolhimento tem características específicas importantes que devem ser levadas em consideração, pois influenciam a abordagem embasadora do curso, o material e o papel do/a professor/a.

PALAVRAS-CHAVE: Acolhimento; Ensino de português; Imigrantes; Língua de acolhimento.

\footnotetext{
* Doutora em Linguística pela Universidade Federal de São Carlos. Professora do Instituto Federal Goiano Campus Ceres.

${ }^{* *}$ Doutora em Estudos Portugueses, Brasileiros e da África Lusofônica pela Universite Paris VIII. Concluiu estágio Pós-doutoral na Universidade Federal do Ceará, com visita acadêmica na Universidade de Aveiro (Portugal). Professora Adjunta da Universidade de Brasília (UnB). Integrante do corpo docente permanente do Programa de Pós-Graduação em Linguística Aplicada da UnB e do Programa de Pós-Graduação em Linguística da Universidade Federal de São Carlos.
} 


\section{Introdução}

A tendência para a crescente diversidade dos fluxos migratórios internacionais baseados em questões econômicas e sociais constitui um dos principais agentes de transformação das sociedades e dos territórios. No que se concerne ao Brasil, a situação não é diferente, o processo de crescimento econômico que o país vinha experimentando nas últimas décadas e a consolidação da democracia constituíram-se elementos atrativos para o aumento do fluxo de imigrantes no País. Estudos empreendidos por Cavalcanti et all (2015) e por Cavalcanti; Oliveira; Araujo (2016), com base em dados estatísticos recentes do Observatório das Migrações Internacionais (ObMigra), demonstram com detalhe, o impacto dos novos fluxos migratórios em solo brasileiro e a necessidade urgente do estabelecimento de políticas públicas para o atendimento das demandas decorrentes dessa realidade.

A questão do refúgio é muito antiga e acompanha a humanidade desde sempre. Seja por questões políticas, religiosas, sociais, culturais, de gênero e até mesmo por desastres naturais, milhares de pessoas tiveram que abandonar sua terra natal, sua casa, em busca de refúgio em países diferentes. No início, a proteção de alguém em países estrangeiros ocorria por motivo de perseguição religiosa, geralmente concedida em templos religiosos, onde os perseguidos podiam se proteger dos perseguidores (BARRETO, 2010).

A partir da Revolução Francesa, com a defesa dos ideais de igualdade e da proteção dos direitos individuais, passos importantes foram dados para o reconhecimento do refúgio, porém, naquela época, dado a criminosos políticos. No entanto, o avanço das relações entre os Estados torna inadmissível a proteção de criminosos, constituindo, assim, que seriam considerados refugiados os indivíduos perseguidos e não criminosos comuns (BARRETO, 2010, p. 14). Essa alteração conceitual pode explicar, de algum modo, a carga cultural negativa que a palavra refugiado(a) carrega até os dias de hoje. Após o fim da Segunda Guerra Mundial, a questão do refúgio tomou proporções gigantescas devido ao contingente expressivo de pessoas forçadas a abandonarem suas pátrias, em fuga da perseguição nazista, da fome e da desordem social provocada pela guerra. 
No momento em que novas migrações reclamam atenção do poder público brasileiro, entendemos ser urgente viabilizar ações formativas de agentes públicos para um acolhimento qualificado. Tal perspectiva requer respeito às especificidades requeridas por essa população marcadamente heterogênea e, nesse contexto, a língua configura-se peça-chave para o estabelecimento da empatia, do reconhecimento e da aproximação, de diferentes culturas, dentro dos princípios de uma educação intercultural.

Este artigo tem como proposição ampliar ideia do ensino de português como língua estrangeira e principalmente (re)formular o conceito de língua de acolhimento. Além disso, as reflexões aqui expostas objetivam mostrar esse conceito aplicado a um curso de português para imigrantes e refugiados, como estratégia de apoio à interação com a sociedade de acolhimento e com o mercado de trabalho.

\section{Relevância do Ensino da Língua-Cultura no Processo de Acolhimento}

Normalmente, os imigrantes em situação de vulnerabilidade enfrentam - além de dificuldades com a língua, com a cultura e com os costumes locais - problemas financeiros, emocionais, de saúde e o preconceito de algumas pessoas, sobretudo por não serem de origem europeia e caucasiana. Organizações de apoio a imigrantes e refugiados no Brasil, como Alto Comissariado das Nações Unidas para Refugiados (ACNUR), criado em 1951 e o Instituto Migrações e Direitos Humanos (IMDH), trabalham para atender as necessidades imediatas apresentadas pelas pessoas em situação de imigração ou refúgio. No que concerne à aquisição da língua portuguesa, esse auxílio inicial é fundamental para que elas/es possam inserir-se na sociedade de maneira satisfatória, pois estudos têm demonstrado que o desconhecimento do idioma é a maior das barreiras para a integração e inserção na sociedade de acolhimento.

Diferentes ações, em sua maioria, estabelecidas pela sociedade civil, sobretudo no formato de voluntariado, vêm o sendo desenvolvidas para atenderem a necessidade de aquisição da língua portuguesa. Entretanto, esse movimento ainda não é suficiente para atender a demanda. As instituições governamentais, além de pouco contribuírem para o 
estabelecimento de políticas concretas relativas ao ensino da língua, ainda não oferecem, de forma sistemática, outros tipos de apoio para essas pessoas, o que dificulta o acesso aos cursos, devido a problemas de custeio das despesas com transporte, alimentação, por exemplo.

Na Europa, países como a França, Bélgica, Alemanha, Portugal, Holanda e outros criaram políticas públicas de acolhimento que abrangem, concomitantemente, o ensino da língua oficial como língua estrangeira ou segunda língua e as questões culturais da comunidade. Além disso, são instalados espaços provisórios para abrigar, dar apoio financeiro e auxílio para encontrarem emprego. A França dispõe nos Fonds d'Action Sociale de serviço voltado ao ensino de francês como língua estrangeira para imigrantes e suas famílias. Da mesma forma, a Alemanha subsidia, por meio de recursos públicos, cursos com o objetivo de promover o ensino da língua e dos aspectos da cultura alemã ${ }^{1}$.

Nessa situação, aprender a língua-cultura do país de acolhimento favorece a inserção sócio profissional das/os imigrantes, pois esse conhecimento produz uma maior igualdade de oportunidades para todos, facilita o exercício da cidadania e potencializa qualificações enriquecedoras para quem chega e para quem acolhe.

A partir dos dados obtidos em um curso de Português como Língua de Acolhimento, destinado a imigrantes e refugiados, podemos afirmar que, assim como o acesso à língua, a preocupação com a interculturalidade, mais do que uma estratégia de encontro ou de comunicação cultural, deve apresentar-se como base de um projeto político de transformação social (RIBEIRO, 2008, p. 4). É no contato e nas diversas situações apoiadas pela relação entre as diferentes culturas e identidades que se ancora o aspecto intercultural. O entendimento de como os valores, as práticas e as crenças afetam o comportamento humano é fundamental para a concepção de programas eficazes que ajudem as pessoas e as nações a exercerem os direitos humanos.

1 Outras informações podem ser encontradas nos sites: www.culture.gouv.fr e www.integration-in-deutschland.de. 
O curso, denominado "Módulo Acolhimento", foi planejado para auxiliar as/os participantes a desenvolverem a Competência Comunicativa Intercultural, adquirindo competência linguística e consciência cultural crítica, com base no pensamento crítico e ação. Os conteúdos foram escolhidos com base nos temas de maior impacto na inserção social dessas pessoas. Dessa forma, o objetivo do referido curso é auxiliar as/os participantes a entenderem como a sociedade de acolhimento se organiza com relação ao trabalho, à moradia, ao acesso à saúde e a relações de gênero, bem como ampará-los na luta contra a opressão e dominação cultural. O desenho curricular foi desenvolvido a partir de uma variedade de textos autênticos de diferentes gêneros, relacionados aos temas citados.

As aulas aqui analisadas ocorreram nas dependências do NEPPE (Núcleo de Ensino e Pesquisa em Português como Língua Estrangeira), na Universidade de Brasília (UnB), dentre o período de agosto de 2013 a outubro de 2015. As atividades foram desenvolvidas no período noturno, às segundas, terças e quintas-feiras e cada etapa teve a duração de três meses. No material foram incluídos os temas: Um pouco sobre mim, Lar e Moradia, Trabalho, Saúde e Relações Sociais. Foram utilizados textos de diferentes gêneros relacionados aos temas de cada unidade, narrativas pessoais e biografias como insumo linguístico e ainda como matéria-prima para a produção escrita das/os alunas/os.

Como as necessidades linguísticas e sociais desse grupo são muito específicas e, portanto, diferentes das necessidades das/os outras/os grupos de estrangeiros atendidas/os pelo NEPPE², compreendemos que o conceito de língua com o qual trabalharíamos deveria, da mesma forma, ser outro. Tal compreensão influenciou todas as fases do curso, desde a metodologia a ser utilizada em sala, à escolha dos temas, dos textos, das imagens bem como o processo de avaliação. Portanto, adotamos o conceito de língua como língua de acolhimento e procuramos produzir um material temático que atendesse às necessidades iniciais de instalação dessas pessoas e a inserção das mesmas na sociedade. Ademais,

${ }^{2}$ A maior parte do grupo atendido pelo NEPPE está ligado à diplomacia instalada na Capital Federal. Esses cursos são pagos. 
procuramos fundamentar o curso em três fatores básicos: as necessidades comunicativas emergenciais das/os aprendentes (Ensino de Línguas sob a perspectiva da Língua de Acolhimento); ênfase no ensino comunicativo por meio da língua em uso (Abordagem Comunicativa / Competência Comunicativa Intercultural); desenvolvimento da conscientização das/os aprendentes (Pedagogia Crítica/Linguística Aplicada Crítica).

Nesse sentido, o objetivo desse curso não se limita à aquisição de conhecimento linguístico, mas visa também a obtenção de conhecimento sobre questões sociais e consciência e visão crítica para evitar manipulação ou dependência. O grupo de trabalho parte da premissa que as/os aprendentes necessitam estar conscientes de como refletir e resistir à hegemonia em suas vidas diárias. Com base na teoria da Pedagogia Crítica, a intenção é que as/os alunas/os e a professora discutam e compartilhem suas experiências de vida para avaliar criticamente os problemas e as diferenças sociais, permitindo que eles/as conheçam e compreendam o modo de vida das/os brasileiras/os, ou das/os brasilienses em uma fase inicial, para que sua adaptação a essa sociedade seja facilitada.

\section{Ensino de PLE no Brasil}

Segundo Almeida Filho (2011, p. 93), o ensino de português para falantes de outros idiomas existe no Brasil desde o período colonial, com o objetivo principal de catequizar a população indígena. No entanto, a prática do ensino moderno dessa língua conta com pouco mais de 50 anos, tendo como marco inicial o a publicação do livro Português para Estrangeiros, de Mercedes Marchand, no ano de $1957^{3}$. Por conseguinte, o ensino de PLE (Português como Língua Estrangeira no Brasil coincide com o ensino de inglês e com as teorias sobre abordagem, método e aquisição de línguas que vigoraram em diferentes épocas.

O histórico do ensino-aprendizagem de línguas, a partir da década de 60, pode ser descrito como um movimento intenso enfatizado pela busca de um método de ensinar 
línguas que seja eficaz. Esse interesse se explicava pela idealização de uma fórmula ou receita pronta que pudesse ser utilizada de maneira igual em diferentes grupos e que surtiria o efeito desejado a todos eles. Num outro momento, influenciado pelas teorias construtivistas e sociointeracionistas, o ensino de línguas transfere o foco do processo de aprender línguas para o aluno, colocando como objetivos principais atender as necessidades e interesses do aprendente, atentando para as diferenças entre os sujeitos e procurando atender de maneira individualizada o ritmo e o crescimento desses sujeitos.

A partir de então, e sob influência da teoria da pedagogia crítica defendida por Paulo Freire, inicia-se um movimento pela valorização por descrever e interpretar as práticas pedagógicas com o objetivo de, a partir dessas experiências, evidenciar as concepções de linguagem e a cultura de ensinar e aprender na sala de línguas. A reflexão sobre a prática insere no cotidiano do professor uma atitude crítica sobre sua maneira de ensinar, provocando nesse profissional, mudanças possíveis que cada vez mais tornem sua prática mais eficiente, por meio da autoavaliação.

O ensino-aprendizagem de PLE movimenta-se segundo as ações e teorias de ensino de outras línguas, uma vez que essas tendências aplicam-se ao ensino de línguas estrangeiras de um modo geral. No entanto, quando comparado ao ensino de outras línguas - como o inglês e espanhol, por exemplo - a prática do ensino de PLE no Brasil ainda é considerada pouco expressiva.

Da mesma maneira, podemos verificar que os cursos de PLE, na maioria dos casos, está concentrado nas universidades e atendem majoritariamente alunos/as estrangeiros que vêm estudar no país. Igualmente, a prática de ensinar PLE se isola, na maioria dos casos, em cursos embasados pela abordagem gramatical, onde o foco central é a gramática, como o próprio nome já diz, pois o principal objetivo desses/as alunos/as é atender às exigências das instituições com relação à aquisição e produção de conhecimento científico.

Contudo, defendemos que o ensino de PLE não deva se restringir ao ensino da estrutura linguística em si. É desejável que, ao aprender uma língua estrangeira, o sujeito 
adquira conhecimentos que extrapolem o simples código linguístico e desenvolvam competências para interagir efetivamente com indivíduos de diferentes culturas e em situações do cotidiano. Dessa forma, o aprendente desenvolve não apenas conhecimento sobre o outro e sobre si, mas relaciona os diferentes modos de organizar a vida, bem como uma consciência cultural crítica, na percepção do que Ferreira (1998, p. 42) chama de "implícito cultural". É necessário considerar que, juntamente com a língua, o aprendente adquire a cultura do povo que a utiliza e compreender que ensinar essa língua-cultura não significa aculturar o aprendente, mas enriquecê-lo e, por esse motivo, o professor precisa ser interculturalmente competente (SILVEIRA, 1998, p. 20). Conforme, Almeida Filho (1993), aprender uma língua não é somente aprender outro sistema, mas construir no discurso ações sociais e culturais apropriadas às diferentes situações comunicativas.

\section{Língua de Acolhimento}

Como já ressaltamos, a barreira linguística é um dos desafios principais enfrentados por imigrantes no que se refere à adaptação a uma sociedade de acolhimento. Como exemplo, trazemos alguns trechos das respostas a questionário aplicado ao grupo de aprendentes participantes do Módulo Acolhimento, turma de 2013. Esse questionário foi aplicado e respondido em inglês por alguns dos participantes. As respostas apresentadas por quatro participantes confirmam nossa hipótese sobre a dificuldade enfrentada pelas/os imigrantes devido a barreira linguística, conforme transcrito a seguir:

Omar: I am living with my family, I am doing a little work that is not enough to pay the house rent/ household thing. Main problem is language.

Mostafa: The main difficulties in the communication with the others, also is very difficult to find a good job with a good salary and for me also complete post-graduation studies.

Kabul: Language problem.

Sayed: Dificuldade com a língua e trabalho e moradia e dinheiro. ${ }^{4}$

\footnotetext{
${ }^{4}$ Dados completos podem ser acessados na tese: Português como língua de acolhimento: um estudo com imigrantes e refugiados no Brasil (SÃO BERNARDO, 2016).
} 
Os excertos em negrito confirmam que os participantes do curso e da pesquisa têm dificuldades para se comunicar em Português e que isso é um entrave para se adaptarem à sociedade de acolhimento. Além disso, fica explícito que tal dificuldade se reflete em todos os âmbitos sociais que requeiram interação em Português, principalmente no que concerne ao acesso a emprego/trabalho.

Ao nos referirmos à língua, aludimos ao construto língua-cultura, entendido como um processo que envolve não só o conhecimento linguístico estrutural de uma língua, mas também suas variantes sociais e os elementos culturais intrínsecos ao pensamento humano, transformados pela língua e transmitidos por meio dela.

Defendemos que um curso dirigido a um público tão específico como o que apresentamos aqui, tenha como premissa a capacitação linguística necessária à comunicação e aos afazeres do dia a dia. Isso implica não somente desenvolver a competência linguística, mas inclui expandir o conhecimento cultural e a capacidade de interação intercultural, propiciando ao aprendente uma sensibilidade cultural, ou ainda uma Consciência Cultural Crítica. Esse conceito (Critical Cultural Awareness) proposto por Byram (1997), no modelo de Competência Intercultural, é descrito como 'habilidade de avaliar criticamente com base em critérios explícitos, pespectivas, práticas e produtos na sua própria cultura e na cultura do outro', permitindo que o aluno se conscientize das diferenças culturais e como essas diferenças interferem na interação e na comunicação, facilitando a integração dessas pessoas à sociedade que os acolhe.

A esse respeito, Byram, em seu livro From Foreign Language Education to Education for Intercultural Citzenship (2008), compara o conceito central da consciência cultural crítica ao conceito de Gagel (2000, apud BYRAM, 2008, p. 164) de Consciência Política:

A pré-condição para o engajamento democrático é quando o cidadão se torna consciente da relação entre destino individual e processos e estruturas sociais. (...) A pessoa politicamente consciente e in- 
formada não deve ser um objeto passivo de política, mas como sujeito deve participar da política (GAGEL apud BYRAM, 2008, p. 164, tradução nossa) $)^{5}$.

Para os imigrantes e refugiados, a apropriação da língua do país de acolhimento não é meramente um fim em si, mas um meio de integração, como ressalta Adami (2009), ao afirmar que essa aprendizagem é uma necessidade ditada pelos imperativos da vida meio exolingual. As urgências do cotidiano em termos de trabalho, transporte, consumo, saúde e relações interpessoais fornecem subsídios e orientação pragmática ao processo de aprendizagem da língua de acolhimento.

Essa perspectiva evidencia-se na narrativa escrita pela professora Lígia, quando evidencia as diferenças entre o ensino de Português para imigrantes/refugiados e aquele destinado a outro público inserido no NEPPE. Ao ao referir-se aos aprendentes em situação de refúgio (SÃO BERNARDO,2016), a professora explicita:

Percebi durante a preparação e no decorrer de minhas aulas que os alunos em contexto de não refúgio objetivavam o aprendizado da língua portuguesa (LP) para trâmites turísticos ou para ampliar seus conhecimentos linguístico-cultural da língua e do Brasil, que pudessem facilitar sua inserção e adaptação na sociedade brasileira, ou para fins de estudos de intercâmbios. Neste contexto, notei que os alunos estavam motivados a aprender LP, no entanto, sua aprendizagem não tinha o caráter de urgência de sobrevivência. Já os alunos em contexto de refúgio objetivavam o aprendizado de LP por uma questão de sobrevivência imediata, para poder desenvolver práticas sociais cotidianas imprescindíveis à sobrevivência, como conseguir um trabalho, ir ao médico, alugar um imóvel, comprar alimentos, etc. Ou seja, os alunos em condição de refúgio apresentam necessidades distintas dos demais alunos em outros contextos, pois a aprendizagem da língua não se direciona somente ao desejo de ampliar conhecimentos linguísticos-culturais de uma outra língua, mas pela necessidade iminente de sobreviver no país de acolhida. (Relato Professora Lígia, p. 1, grifos nossos)

\footnotetext{
5 "The pre-condition for democratic engagement is that the citizen becomes aware of the relationship between individual destiny and social processes and structures. (...) The politically aware and informed person should not be a passive object of politics, but as a subject should participate in politics".
} 
A necessidade de aprender por questão de sobrevivência marca o relato da professora. Percebemos que o objetivo, nesse caso, se difere muito dos objetivos antes tomados como mais comuns e que, muitas vezes, serviam de base para a preparação de cursos e elaboração de materiais de ensino de línguas. Conforme a professora relata, as/os imigrantes estão nesse curso aprendendo português "para poder desenvolver práticas sociais cotidianas imprescindíveis à sobrevivência”.

Dessa maneira, quando nos referimos à língua-alvo como língua de acolhimento, ultrapassamos a noção de língua estrangeira ou de segunda língua. Para o público adulto, recém-imerso em uma realidade linguístico-cultural não vivenciada antes, o uso da língua estará ligado a um saber diversificado como: saber agir e saber fazer. Além das inúmeras tarefas linguístico-comunicativas que devem ser realizadas nessa língua e a possibilidade de tornar-se cidadão desse lugar, cultural e politicamente consciente, participando como sujeito da sociedade. Grosso (2010) explica a escolha pelo conceito língua de acolhimento, definindo a relação entre a língua e o contexto a que ela se aplica:

Orientada para a ação, a língua de acolhimento tem um saber fazer que contribui para uma interação real, a vida cotidiana, as condições de vida, as convenções sociais e outras que só podem ser compreendidas numa relação bidirecional (GROSSO, 2010, p. 71).

A autora defende ainda que "ao se operacionalizar a língua de acolhimento em conteúdos de ensino-aprendizagem, o seu âmbito ultrapassa largamente o domínio profissional", no entanto, esse nível é de extrema importância para a integração do indivíduo à nova sociedade. Apesar disso, as necessidades comunicativas estão ligadas a tarefas e situações que divergem da cultura de origem e que perpassam por diferentes setores da vida, como a educação, o trabalho, a saúde, a moradia e as relações interpessoais.

A experiência vivenciada no Projeto "PROACOLHER" ajuda na compreensão e na ampliação do que se entende por "acolhimento", conforme apontam Barbosa e São Bernardo (2017) quando afirmam que língua de acolhimento 
(...) refere-se também ao prisma emocional e subjetivo da aprendizagem dessa nova, sem perder de vista s relação conflituosa que se apresenta no contato inicial do imigrante com a sociedade acolhedora. Esse conflito é previsível, a julgar pela situação de tensão e de vulnerabilidade que, em geral, essas pessoas enfrentam quando chegam a um país estrangeiro, nem sempre com a intenção de nele permanecer. Sob esse ponto de vista, destacamos que esse conceito reconhece sentimentos de rejeição e dou descaso do(a) aprendente em relação à aquisição dessa nova língua que não foi escolhida por ele(a). (BARBOSA; SÃO BERNARDO, 2017, p. 436).

Dessa forma, a prática de ensinar Língua de Acolhimento impacta o papel do/a professor/a e a metodologia a ser usada nesse contexto de ensino, pois como afirma Freire (1982), o/a professor/a deve estar aberto ao diálogo. Por esse motivo, consideramos que a utilização de instrumentos que possibilitem que as/os aprendentes sejam ouvidos, que descentralizem o poder no ambiente de sala de aula, que proporcionem aos aprendentes momentos em que utilizem a língua-alvo como ferramenta para se fazerem percebidos, para contarem a sua história, contribua para essa "humanização" sugerida por Freire.

Através do diálogo, a relação professor/a-aluno/a passa por uma metamorfose positiva e não por uma relação de dominação e submissão. Pelo contrário, ela se torna um diálogo construtivo entre parceiros mais ou menos co-iguais. Para aprendentes adultas/os, as tensões envolvidas no processo de aprender são amenizadas quando as/os professores/as são reconhecidos como pessoas reais. Ao utilizar-se de uma prática não-autoritária, o/a professor/a leva as/os alunas/os a explorarem e expandirem a sua identidade através das fronteiras, além de ajudá-las/os a enfrentarem fatos e refletirem sobre conceitos até então escondidos pela hegemonia. O diálogo, nessa perspectiva, envolve não apenas discussões aluno/a -professor/a, mas também entre as/os alunas/os, uma vez que o pensamento crítico deve envolver todos os processos de interação.

As professoras Lígia e Ingrid falam sobre o papel da professora nesse contexto específico (SÃO BERNARDO, 2016):

Para perceber todas essas questões que envolveram os meus alunos e todo o contexto, tive que diariamente trabalhar com a minha 
sensibilidade de percepção, de interculturalidade e, sobretudo, ativar a alteridade. Por muitas vezes, tentei me colocar, me imaginar na situação deles e então simular, mesmo que fictício, sentimentos, vontades e ações. (...) me atentei para uma questão crucial nesse ensino, que é saber identificar e valorizar as habilidade dos alunos, assim com sua história de vida e sua cultura. E por meio dessa valorização, tentar os ajudar a melhorar a baixa autoestima e diminuir o sentimento de desorientação que acomete a muitos, tentar, por meio desse ensino realmente acolher e os preparar para um futuro nesse novo país, nessa nova cultura. (Relato Professora Lígia, p. 3-4, grifos nosso.)

Essa percepção ${ }^{6}$ aparece no professor no dia a dia, nas conversas, nas brincadeiras, nas leituras. Acredito que pode vir de maneira sutil, às vezes. Em outras, chega apressadamente e te move em toda sua prática. Dessa forma, você direciona o ensino da língua para essas necessidades, que você percebe nos alunos e que você acaba refletindo que seriam importantes. O professor tem que estar aberto para responder, perguntar, silenciar, quando for necessário. É um convívio que lhe ensina muito e que você, como profissional, repensa muito suas práticas, suas atitudes, suas referências. (talvez, colocar-se no lugar do outro funciona muito bem nesse caso). (Relato Professora Ingrid, p. 1, grifo nosso.)

Observamos nas falas das professoras a consciência da necessidade de se colocarem no lugar dessas pessoas e tentarem entender, mesmo que minimamente, o que elas estão vivendo nessa nova situação. O contexto de acolhimento exige do/a professor/a uma atenção, um cuidado e uma aproximação mais eficaz de quem aprende. A professora, na maioria dos casos, é a única "nativa" com quem a/o aprendiz tem contato. Portanto, o papel da professora vai além de ensinar a língua, pois passa a ser um apoio, um porto seguro a quem o/a imigrante recorre para buscar auxílio em para resoluções de problemas em diferentes setores do cotidiano.

Da mesma maneira, todo o curso, a metodologia e o material usado é influenciado pelo conceito de língua de acolhimento. $\mathrm{O}$ uso de temas que sejam próximos à realidade

${ }^{6} \mathrm{~A}$ professora fala sobre a percepção das necessidades, dos sentimentos e das expectativas dos/as alunos/as. 
em que vivem ou viveram os/as alunos/as contribui para a aquisição da língua de acolhimento, uma vez que aproxima o aluno dessa língua e o incentiva a produzir textos, narrativas pessoais, que contem sua própria história. Além disso, abordar assuntos de seu interesse no material didático pode fazer com que a/o aprendente sinta-se acolhida/o e atendido naquilo que lhe é mais premente naquele momento. Por esse motivo, é importante que o material a ser utilizado com esses grupos, em específico, apresente unidades que estejam de acordo com o que eles vão enfrentar ou já enfrentam no seu cotidiano no país estrangeiro. Assim, temas voltados à saúde, trabalho, dar e receber informações, podem estar associados à leitura e produção de textos que priorizem a realidade enfrentada por eles e que façam sentido para o uso da língua no dia-a-dia dessas pessoas, permitindo que eles consigam expressar-se por meio da língua.

Almeida Filho (2002, p. 12) nos diz que "a nova língua para desestrangeirizar vai ser aprendida para e na comunicação sem se restringir apenas ao domínio de suas formas e do seu funcionamento enquanto sistema". Para que encontre sentido no que se está aprendendo, é preciso que o aprendizado seja tomado em conjunto e em relação a outras coisas. Portanto, é necessário que o aprendiz se envolva em situações reais de interação e de comunicação efetiva na nova língua, o que pode ser facilitado por meio do ensino baseado em temas.

Levando em consideração que a aquisição da língua traz consigo o conhecimento da cultura que ela representa, da maneira com que os falantes dessa língua enxergam as situações do cotidiano, do como fazer, como agir, como solucionar os problemas do diaa-dia, o ensino da língua de acolhimento objetiva ir além da simples aceitação desses fatores socioculturais por parte do/as alunos/as. Esse conceito de ensino de língua pressupõe que haja a comparação entre a língua-cultura que se adquire e aquela que já lhe é de pertencimento, realizando uma troca de experiências de vida e modos de ser diferentes, analisando de forma crítica a relação estreita entre a língua, o modo de pensar e de agir e a construção das identidades de um grupo social. 
Assim, admitimos que o professor precisa estar ciente de que a sala de aula de um curso de PLE é um dos maiores exemplos de um ambiente intercultural e que pode ser, sim, um ambiente autêntico onde relações autênticas são experimentadas. Nesse contexto, a comunicação deve se dar através do princípio da solidariedade, da verossimilhança e da transformação social. A língua como elemento social de mudança, capaz de auxiliar o sujeito na transformação social e pessoal (FREIRE, 1970).

\section{Conclusão}

Os resultados da pesquisa empreendida mostraram que o ensino de segundas línguas ou línguas adicionais em contexto de acolhimento traz especificidades que permitem o uso de um conceito diferente para o ensino de línguas, que chamamos de língua de acolhimento.

Ensinar língua de acolhimento requer uma abordagem crítica e de empoderamento que promova a transformação social e interfere no papel do/a professor/a, como agente de transformação e de facilitador do processo de integração e de reconhecimento do imigrante como partícipe da sociedade de acolhimento. Além disso, o material deve estra em consonância com as necessidades emergenciais enfrentadas pelas/os imigrantes.

As professoras, por meio dos relatos, afirmam que a experiência ensinou-as a entender uma nova forma de ensinar português, de maneira mais humanizadora, buscando a integração dos/as alunos/as por meio da ação de acolhimento. Verificamos que através da abordagem de ensino, do material e das atividades, os/as alunos/as conseguiram construir a confiança em aprender e falar português, tornando-se gradualmente competentes. Tal evidência fortalece o nosso desejo de manter e ampliar a realização do curso, atendendo mais pessoas que tomam o Brasil como novo lar para (re)construção de suas vidas e aberturas de novas trajetórias.

O conceito de língua de acolhimento serviu (e tem servido) de base para o estabelecimento da abordagem e da metodologia usada. Além disso, ela guiou a produção do 
material didático e o papel e a atitude das professoras na sala de aula, ajudando-nos compreender o papel dessa concepção de língua para a inserção social, no desenvolvimento da sensibilidade intercultural e no processo de socialização das pessoas em situação de imigração forçada. Por meio dos resultados do estudo aqui brevemente relatado, as/os aprendentes demostraram que se sentiram acolhidos durante o curso e perceberam avanços na sua integração à sociedade e, em específico, aos ambientes sociais que frequentam cotidianamente.

\title{
TEACHING OF PORTUGUESE AS A LANGUAGE OF RECEPTION: EXPERIENCE IN A PORTUGUESE COURSE FOR IMMIGRANTS AND REFUGEES IN BRAZIL
}

\begin{abstract}
Brazil has received a considerable number of immigrants of different nationalities from South America, Africa and countries like Bangladesh and Pakistan, but mainly Haitian and Syrians. However, there are no explicit public policies of teaching Portuguese to these people in Brazil. Civil society and some universities have begun a work to try to minimize the problem of the difficulty in the integration of immigrants due to communication problems. Nevertheless, there is a need to expand and discuss the concept of host language and a need of researches that promote social integration actions, through the teaching of the language in a host context. This article discusses the (de)(re)construction of the concept of host language and it presents the experience of the Portuguese language course as a host language, as part of the Research Project: PROACOLHER: Portuguese as Reception Language, offered at NEPPE (Center of Teaching and Research in Portuguese as a Foreign Language) at University of Brasília. The action research has brought us data we consider relevant to affirm that the teaching Portuguese in the host context has important specific characteristics that must be taken into account, since they influence the basic approach of the course, the material and the role of the teacher
\end{abstract}

KEY-WORDS: Host; Host language; Immigrants; Portuguese teaching.

\section{BIBLIOGRAFIA}

ACNUR. Dados sobre o refúgio no Brasil: uma análise estatística (2010-2014). 2014. Disponível em: http://www.acnur.org/t3/portugues/recursos/estatisticas/dados-sobre-refugio-nobrasil/. Acesso em: 06 de outubro de 2016. 
ADAMI, H. La formation linguistique des migrants, CLE international. 2009.

ALMEIDA FILHO, J.C.P. Dimensões comunicativas no ensino de linguas. $1^{\mathrm{a}}$. ed. Campinas: Pontes. 1993.

Linguística aplicada: ensino de línguas e comunicação. Campinas,SP: Pontes Editores e Arte Língua. 2002.

. Conbecer e desenvolver a competência profissional dos professores de LE. In:Contexturas: Ensino Crítico de Lingua Inglesa. São Paulo: APLIESP, n.9. p. 9-19. 2006.

Fundamentos de Abordagem e Formação no Ensino de PLE e de Outras Linguas. Campinas, SP: Pontes Editores. 2011.

BARRETO, L. P. T. (Org.). Refúgio no Brasil: a proteção brasileira aos refugiados e seu impacto nas Américas. - 1. ed. - Brasília: ACNUR, Ministério da Justiça. 2010. Disponível em: http://www.acnur.org/t3/fileadmin/Documentos/portugues/Publicacoes/2010/Refugio_no_Brasil.pdf?view=1. Último acesso em 26 de novembro de 2016.

BARBOSA, L. M. A; SÃO BERNARDO, M. A Português para Refugiados: Especificidades para Acolhimento e Inserção. In: SIMÕES, D. M. P. ; FIGUEIREDO, F. J. Q.. (Org.). Metodologias em/ de linguística aplicada para ensino e aprendizagem de linguas. Campinas, SP: Pontes Editores, pp. 269-278. 2014.

; SÃO BERNARDO, M. A. The Role of Language in Social Integation of Refugees. In: GOROVITZ, S., MOZZILLO, I. (eds.). Language Contact: Mobility, Borders and Urbanization. Newcastle upon Tyne: Cambridge Scholars Publishing, p. 107-118. 2015.

; SÃO BERNARDO, M. A. Português para Refugiados: Especificidades para Acolhimento e Inserção.. In: SIMÕES, D. M. P. ; FIGUEIREDO, F. J. Q.. (Org.). Metodologias em/de linguística aplicada para ensino e aprendizagem de linguas. Campinas, SP: Pontes Editores, p. 269-278. 2014.

; SÃO BERNARDO, M. A. Língua de Acolhimento. In: CAVALCANTI, L. [et al.], (org.). Dicionário crítico de migrações internacionais. Brasília: Editora Universidade de Brasília, p. 434-437. 2017.

BYRAM, M. Teaching and assessing intercultural communicative competence. Clevedon: Multilingual Matters. 1997.

. Cultural studies in foreign language education. Clevedon: Multilingual Matters. 1989.

. Language and Culture Learning for European Citizenship, in: BEVERIDGE, M. C. \& REDDIFORD, G. (eds.). Language and Education, v.6, n.2, pp. 165-176. 1992.

. Routledge encyclopaedia of language teaching and learning. London: Routledge. 2000. 
. From foreign language education to education for intercultural citizenship. Clevedon: Multilingual Matters. 2008.

CAVALCANTI, L.; OLIVEIRA, T.; TONHATI, T.; DUTRA, D., A inserção dos imigrantes no mercado de trabalho brasileiro. Relatório Anual 2015. Observatório das Migrações Internacionais; Ministério do Trabalho e Emprego/Conselho Nacional de Imigração e Coordenaççao Geral de Imigração. Brasília, DF: ObMigra, 2015.

; OLIVEIRA, T; ARAUJO, D.. A inserção dos imigrantes no mercado de trabalho brasileiro. Relatório Anual 2016. Observatório das Migrações Internacionais; Ministério do Trabalho/Conselho Nacional de Imigração e Coordenaççao Geral de Imigração. Brasília, DF: ObMigra, 2016.

FERREIRA, I. A. Interface Português/Espanhol, in:. ALMEIDA FILHO, J. C. P. (Org.). Parâmetros Atuais no Ensino de Português Lingua Estrangeira. $1^{\circ}$ SAPEC, Campinas - São Paulo: Editora Pontes. 1998.

FREIRE, P. Pedagogia do Oprimido, Paz e Terra, Rio de Janeiro. 1970. . Ação cultural para a liberdade. 6. ed., Rio de Janeiro: Paz e Terra. 1982.

GROSSO, M. J. R. Lingua de acolbimento, lingua de integração. Horizontes de Linguística Aplicada, v. 9, n.2, p. 61-77. 2010.

SÃO BERNARDO, M. A. Português como lingua de acolhimento: um estudo com imigrantes e refugiados no Brasil. São Carlos: Programa de Pós-graduação em Linguística, Universidade Federal de São Carlos, 206 fs, Tese de Doutorado. 2016.

; FERNANDES, F. A. ; BARBOSA, L. M. A. (Inter)Açōes dos elementos culturais no livro didático de LE (Inglês). Revista Desempenho, v. 21, p. 1-12. 2014.

; BARBOSA, L. M. A. Interações Virtuais e Competência Intercultural. In: BARBOSA, L. M. A (Org.). (Inter)ações (inter)culturais no ensino-aprendizagem de linguas. 1ed.Campinas: Pontes Editores, v. 1, p. 143-166. 2014.

; ZOCARATTO, B. L. ; FERREIRA, M. E. S.; GOMES, S. M. C. Suficiência e adequação dos componentes da competência comunicativa de um professor de LE sob análise. Revista Desempenho, v. 10, p. 3. 2009.

SILVEIRA, R. C. P. da (Org.). Português Língua Estrangeira: perspectivas. São Paulo: Cortez. 1998. 
WIDDOWSON, H. G. O ensino de linguas para a comunicação. Tradução de José Carlos P. de Almeida Filho. Campinas, SP: Pontes, 1991.

Recebido em: 22/07/2018.

Aprovado em: 08/08/2018. 